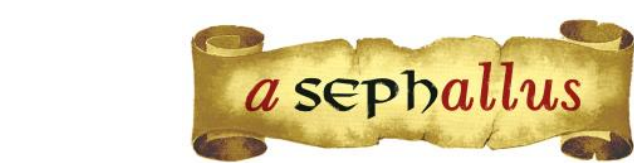

Revista aSEPHallus de Orientação Lacaniana

Núcleo Sephora de Pesquisa sobre o Moderno e o Contemporâneo

ISSN $1809-709 \mathrm{X}$

\title{
Freud e a Grécia antiga: uma leitura do processo de cronificação em saúde mental
}

\author{
Camila Quinteiro Kushnir \\ Psicanalista \\ Psicóloga pela Universidade Federal do Rio de Janeiro/UFRJ (Rio de janeiro, Brasil) \\ Pós-graduada em Clínica Psicanalítica pelo Instituto de Psiquiatria da Universidade Federal do Rio de \\ Janeiro/IPUB-UFRJ (Rio de Janeiro, Brasil) \\ Mestranda pela Universidade Federal do Rio de Janeiro /UFRJ (Rio de Janeiro, Brasil) \\ Membro em formação do Corpo Freudiano Escola de Psicanálise/CFEP (Rio de Janeiro, Brasil)
}

E-mail: camilaqk@yahoo.com.br

\begin{abstract}
Resumo: O presente artigo tem como objetivo examinar a discussão que se realiza no Brasil sobre uma nova forma de cronificação nos ambulatórios de saúde mental. Será destacada a tensão entre a ética do bem-estar com um saber institucional legitimado a respeito dos usuários, e a dimensão ética do bem-dizer na qual a psicanálise sustenta-se orientada pela via do desejo singular a cada sujeito. Neste percurso, será traçado um paralelo entre a tradição grega e a era moderna pelo modo como exploram a sexualidade. A psicanálise, em certa medida, retoma a antiguidade pelo valor que atribui à potência sexual, em detrimento dos objetos tomados pela pulsão.
\end{abstract}

Palavras-chave: cronificação; reforma psiquiátrica; pulsão; ética.

Freud et I'Antiquité grecque: une lecture du processus de chronicisation en santé mentale

Cet article vise à examiner la discussion qui a lieu au Brésil sur une nouvelle forme de chronicisation dans les ambulatoires de santé mentale. Il sera mis en évidence la tension entre l'éthique du bien-être avec un savoir institutionnel légitime sur les usagers, et la dimension éthique du bien-dire sur laquelle la psychanalyse se fonde orientée par le désir singulier à chaque sujet. Dans cette démarche, il va tracer un parallèle entre la tradition grecque et l'ère moderne par la façon dont elles explorent la sexualité. La psychanalyse, dans une certaine mesure, reprend l'Antiquité par la valeur qu'elle attache à la puissance sexuelle, au détriment des objets pris par la pulsion.

Mots-clés: chronicisation; reforme psychiatrique; pulsion; éthique.

\section{Freud and ancient Greece: a reading of the chronification process in mental health}

This article aims to examine the discussion that takes place in Brazil about a new form of chronification in mental health institutions. We will highlight the tension between the ethics of well-being with a legitimized institutional knowledge about the users, and the ethical dimension of "well saying" in which psychoanalysis is sustained, oriented by the singular desire in each subject. On the course of this exaination, a parallel will be drawn between the Greek and the modern tradition through the way in which sexuality is explored. Psychoanalysis, to some extent, reclaims antiquity for the value atributed to sexual potency, in detriment of objects taken by the drive. Key-words: chronification; psychiatric reform; drive; ethics. 


\title{
Freud e a Grécia antiga: uma leitura do processo de cronificação em saúde mental
}

\author{
Camila Quinteiro Kushnir
}

\section{Introdução}

Com a criação de uma Política Nacional de Saúde Mental pautada no movimento da reforma psiquiátrica brasileira, que tem pouco mais de vinte anos, as instituições de tratamento vêm buscando converter o modelo hospitalocêntrico por uma rede de serviços territoriais de atenção psicossocial, visando eliminar o estatuto de exclusão de pacientes que sofrem de algum tipo de transtorno mental (Brasil, 2001).

Dentre esses dispositivos estão os ambulatórios, que constituem uma das portas de entrada na rede ${ }^{1}$. Através do trabalho realizado em um desses locais percebeu-se certa singularidade em seu funcionamento. Grande parte dos casos absorvidos permanecia em tratamento por longos períodos - 10 a 30 anos -, passando por diferentes especialistas.

Ademais, com o tempo, as atividades cotidianas desses usuários começavam a gravitar em torno do tratamento. Um paciente aproveitava a ida aos atendimentos para sair de casa e fazer de tudo. Em outros dias, passava a maior parte do tempo na cama. Já outro encontrava como dilema não poder aceitar um emprego melhor, pois com um aumento da carga horária teria que diminuir sua frequência no ambulatório. Situações que representavam para além de um sofrimento, certa dependência da instituição.

Este fenômeno, em crescimento no país, vem sendo descrito na literatura como uma nova cronificação dos dispositivos substitutivos de saúde mental. Em documento recente do Ministério da Saúde (2010), os ambulatórios foram tidos como um desafio à consolidação dos pressupostos da reforma psiquiátrica. Existiriam entraves na articulação desses locais com os demais órgãos de saúde, prejudicando a chegada e encaminhamento dos usuários, além de um processo de burocratização que tenderia à mecanização dos atendimentos.

A respeito da cronificação de muitos pacientes em ambulatórios, Desviat (1999) comenta que estes seguiriam um acompanhamento irregular com os profissionais, o que dificultaria o avanço do tratamento. Barros (2003), por outro lado, salienta que a permanência por tempo indeterminado do usuário atrela-se, muitas vezes, à dificuldade de suas ações fora desses serviços, como a adoção de novas convivências na comunidade e espaço urbano.

Restritos a esse "circuito especial" da instituição como espaço principal de sociabilidade, a dependência do paciente autoengendrar-se-ia (Severo, 2009). Para Santos (2007) o trabalho nos ambulatórios não seguiria um constante questionamento acerca dos efeitos que continuam a ocorrer, mesmo após a reforma psiquiátrica, como a estigmatização do usuário e a hierarquização entre os membros da equipe, o que favorece o desenvolvimento da cronificação.

Recorrendo-se à psicanálise, percebe-se como Freud já em 1912 observara um processo semelhante nas instituições de tratamento: 
A transferência erótica não possui efeito tão inibidor nas instituições, visto que nessas, tal como acontece na vida comum, ela é encoberta ao invés de revelada. Mas se manifesta muito claramente como resistência ao restabelecimento, não, é verdade, por levar o paciente a sair da instituição - pelo contrário, retém-no aí mas por mantê-lo a certa distância da vida. (Freud, 1912/1996, p. 141)

Haveria, assim, nas instituições um movimento que através da transferência erótica produziria a retenção do paciente e o afastamento de seu interesse pela vida, acarretando a resistência deste ao restabelecimento. Freud, contudo, ao falar de restabelecimento, ou mesmo cura pela psicanálise, afasta-se em grande medida da compreensão que a reforma psiquiátrica promulga ter sobre esses termos. Se há uma ação de cronificar indivíduos em vigência nos serviços ambulatoriais pode-se dizer que o interesse da psicanálise está na parte que cabe a cada envolvido neste processo. Mais que isso, em quais seriam as resistências presentes na dinâmica de cada tratamento que se prolonga no tempo.

O objetivo deste trabalho vem a ser, assim, examinar a discussão que se realiza sobre o aumento da cronificação nos ambulatórios de saúde mental, especificamente nos casos de neurose. Visar-se-á destacar a tensão entre uma leitura que considera conhecer o que seria melhor para cada usuário, e a dimensão ética na qual se sustenta a psicanálise orientada pela via do desejo singular a cada sujeito.

Neste percurso será traçado um paralelo entre a tradição grega e a modernidade no modo como exploram a relação entre a pulsão sexual e os objetos tomados por ela. Se Freud (1908/1996) considera a moral sexual propagada na civilização um dos fatores para o incremento das psiconeuroses, o que é possível dizer sobre o crescimento dos casos de pacientes neuróticos crônicos em ambulatórios nos quais vigora um saber assegurado sobre eles?

\section{Os paradigmas sexológicos da antiguidade e modernidade}

Há quem diga que a psicanálise trata em sua clínica unicamente de problemas individuais. Referindo-se a uma escuta singular, do caso a caso, esta privilegiaria aquele que fala em detrimento do meio que o cerca. Freud, porém, preocupou-se em esclarecer este mito ao longo de sua obra.

Apenas em circunstâncias excepcionais a relação do indivíduo com o social seria desconsiderada. O outro como modelo para o sujeito seria tão alvo da investigação psicanalítica quanto os processos psíquicos de cada analisando. "A psicologia individual também é ao mesmo tempo psicologia social nesse sentido ampliado, porém inteiramente legítimo" (Freud, 1921/2013, p. 35).

Já em 1905, Freud ao debruçar-se sobre a teoria da sexualidade, a partir de seus três ensaios, descreve a importância dos diversos objetos tomados pela pulsão sexual na tentativa de 
satisfazer-se. Para isso, ele parte de considerações morais da época vitoriana que viam na homossexualidade um símbolo das ditas aberrações sexuais. Nesse contexto, o sexo só deveria realizar-se entre um homem e uma mulher através de um casamento monogâmico com objetivos de reprodução. Não foi coincidência para Freud (1908/1996) que este cenário vivido no cerne da modernidade possibilitou o lugar que a psicanálise veio a ter junto às pacientes histéricas que relatavam seus conflitos entre o que desejavam e como deveriam comportar-se.

Indagando-se sobre as mudanças culturais e a influência da sociedade em cada indivíduo, até mesmo no surgimento das neuroses, em uma nota de rodapé acrescentada em 1910 ao seu primeiro ensaio de 1905, Freud salienta uma mudança ocorrida no paradigma sexológico da humanidade. Na antiguidade a exaltação da pulsão sexual era direcionada à força da pulsão [drang]. A potência sexual dos cidadãos da pólis representava um símbolo de poder. Na era moderna, contudo, o que passou a ser destacado, e mesmo controlado, foram os objetos alvos da pulsão.

Era comum entre os gregos o desejo de homens maduros por efebos; púberes que ainda mantinham semelhança física com as mulheres. Freud toma este fato para realizar um contraponto entre a modernidade e os antigos quanto à construção das categorias de aberrações sexuais.

Na Grécia o sexo entre homens não era repudiado, mas sim aceito e incitado. Contudo, existiam certas regras a serem seguidas nesta prática. $O$ homem só poderia ter prazer com objetos considerados inferiores: escravos, efebos ou mulheres. A penetração visava enaltecer o domínio dos cidadãos; uma forma de exercício de seus direitos. Desse modo, o objeto era tido como secundário, pois sua excitação sexual era menosprezada, e até rechaçada. Efebos só poderiam exercer sua potência sexual quando do nascimento de pelos em sua face, isto é, quando perdiam as características femininas que os demarcavam como não cidadãos (Lopes, 2011).

Com a decadência política da cidade grega antiga os grandes sistemas de Platão e Aristóteles foram dando lugar a importantes escolas filosóficas na época helenística, como o epicurismo e estoicismo que aconselhavam a moderação e o controle das paixões. A contenção do desejo e fidelidade no casamento passaram a ser incentivadas, mas não normatizadas (Foucault, 2009).

Foi apenas com o cristianismo, e seu primeiro grande representante Santo Agostinho, que a sexualidade direcionada à satisfação tornou-se proibida para ambos os sexos. A reprodução converteu-se no objetivo da união entre os corpos masculino e feminino, e a libido, enquanto energia, dirigida a Deus. Esta deveria ser controlada pela razão, tornando-se vergonha para a consciência (Lopes, 2011).

Nesse sentido, pode-se dizer que a ideia de um destino outro para a pulsão que não a satisfação sexual aproxima-se do conceito freudiano de sublimação. Através dela o prazer é obtido pelos investimentos em objetos culturalmente aceitos, como na arte e no trabalho. Freud (1930/2014) considerou esta vicissitude da pulsão mais fina e mais elevada que a satisfação por metas sexuais diretas, sendo ela que propiciaria a manutenção duradoura dos laços sociais. Para ele (1908/1996), ainda assim, esta não seria a principal via tomada pela pulsão. Apenas poucos seres 
humanos teriam aptidões especiais para a sublimação de seus impulsos, e isto em excesso acarretaria perturbações psíquicas, como o surgimento de sintomas.

Ao examinar o desenvolvimento das pulsões, Freud (1905/1996) averiguou como na tenra infância são as influências externas como a educação que levam a criança a repudiar algumas ações de ordem sexual. O asco, a vergonha e a própria moralidade, enquanto forças anímicas de cada indivíduo fariam resistência à expressão e satisfação das pulsões. O sexual já presente no bebê, em função de seu corpo erogeneizado pelos cuidados maternos, será para toda a vida uma sexualidade perversa polimorfa. O corpo seria inicialmente o modo privilegiado de obtenção de prazer pelas pulsões parciais. Apenas com a chegada da puberdade haveria a subordinação dessas pulsões autoeróticas às zonas genitais, servindo à função reprodutora.

Por isso mesmo o escândalo instaurado por Freud no início do século XX ao considerar a existência de uma sexualidade infantil. Na sociedade judaico-cristã da época o sexo e a sexualidade coadunavam-se. Apenas os genitais seriam excitáveis, tendo como finalidade a reprodução. Não era isto, entretanto, o que Freud (1905/1996) pudera observar. O bebê ao apaziguar sua fome, por exemplo, também obtém prazer sexual no contato de sua boca com o seio materno. No começo, o prazer oral é alcançado nesse encontro, mas a descoberta de novos objetos externos pelo infante propicia diversas outras formas de satisfação.

A sexualidade entendida por Freud como polimorfa é também perversa, pois mesmo após o primado da genitalidade o ser humano continuará buscando o prazer fora da via da reprodução. Por mais que a moralidade exerça a repressão dos impulsos sexuais, eles continuam em atividade orientando-se para a descarga através de diferentes objetos que não os genitais, ou mesmo os genitais sem que haja a procriação.

Birman (2010a) evidencia como de modo astuto Freud em seus três ensaios aproxima a perversidade polimorfa da ideia de potência sexual dos gregos. Por essa leitura, a intepretação freudiana sobre a sexualidade não seria moderna, como foi o surgimento da psicanálise. Freud retoma a tradição grega ao dar destaque à pressão exercida pela pulsão que busca satisfazer-se, mesmo que forças internas e externas - recalque e repressão - venham opor-se $a$ isso.

A força da pulsão é seu fator motor. Ela é a essência da pulsão, pois expressa a ligação entre o psíquico e o somático e promove sua ação. Pela percepção de um incômodo no corpo busca-se a memória de imagens de alívio no psiquismo. Isto evidencia uma exigência de trabalho que o somático faz sobre o psíquico, levando a pulsão à atividade, investindo em objetos para que ocorra descarga. É essa força impelente que permite os encontros entre o ser humano e o mundo (Freud, 1915/2004).

Se os objetos na antiguidade eram inferiores devido ao valor posto sobre a potência sexual, para Freud eles são secundários pela variabilidade que representam na busca do prazer. Nenhum objeto sobrepõe-se a outro em importância, já que à priori não se sabe o que é capaz de apaziguar a tensão. "Ao longo dos diversos destinos que a pulsão conhecerá, o objeto poderá ser substituído por intermináveis outros objetos" (Freud, 1915/2004, p. 149). 
Entretanto, a pulsão pode perder sua mobilidade através de uma fixação a determinados modos de satisfação. Parece ser em relação a isso que Freud chama a atenção ao falar dos efeitos transferenciais que acarretam a retenção de pacientes em tratamento. Uma transferência erótica com a instituição poderia representar certa resistência através de uma "adesividade da libido", isto é, uma dificuldade no desinvestimento libidinal em determinado objeto, ou no deslocamento dele para outro (Freud, 1937/1996, p. 274).

É importante, para que ocorra o tratamento, que se estabeleça uma transferência com a instituição. Contudo, se isto é acompanhado de um afastamento do interesse por outras formas de investimento libidinal, faz-se importante a discussão do papel que a instituição e seus profissionais passam a desempenhar.

\section{Expressão do desejo ou onipotência do objeto: a que serve a força da pulsão?}

Em 1915 no texto Observações sobre o amor transferencial Freud orienta que em situações de enamoramento o que é dito pelo paciente presta-se a desviá-lo do processo analítico. Passa a querer ser correspondido pelo analista, fixando-se neste amor, resistindo a trabalhar sobre o material recalcado. Não caberia ao analista corresponder, nem mesmo levar o paciente à renúncia deste amor, mas sim manter atuante a força pulsional em jogo, porém a serviço do tratamento, da rememoração. "Se deve permitir que a necessidade da paciente nela persista, a fim de poderem servir de forças que a incitem a trabalhar e efetuar mudanças" (Freud, 1915[1914]/1996, p. 214).

Em 1918 em "Linhas de progresso na terapia psicanalítica", outra recomendação:

Qualquer analista que, talvez pela grandeza do seu coração e por sua vontade de ajudar, estende ao paciente tudo o que um ser humano pode esperar receber de outro, comete o mesmo erro econômico de que são culpadas as nossas instituições não-analíticas para pacientes nervosos. O único propósito destas é tornar tudo tão agradável quanto possível para o paciente, de modo a este poder sentir-se bem ali e alegrar-se de novamente ali refugiar-se das provações da vida. Ao fazê-lo, não tentam dar-Ihe mais força para enfrentar a vida e mais capacidade para levar a cabo as suas verdadeiras incumbências nela. (Freud, 1919[1918]/1996, p. 206-207)

É, assim, na tentativa que o anseio do paciente persista enquanto libido a ser direcionada para o trabalho analítico que Freud (1915[1914]/1996) postula a regra da abstinência. Sem responder às demandas, tal como exigidas pelos pacientes, mantém-se a força pulsional atuante. 0 cuidado do analista deve ser para que o sofrimento do paciente não se dissipe prematuramente, até que os conteúdos recalcados possam ser suficientemente trabalhados.

Outro fator, colocado pela transferência, é o poder tido pelo analista, bem como pela instituição. 0 paciente, passível de ser sugestionado por quem dirige o tratamento, pode passar a 
comportar-se como considera ser o esperado dele. Segundo Birman (2010b), o poder médico atrelado às práticas distintas da psicanálise continuou a acossar Freud mesmo com as inovações técnicas propostas pelo método analítico. $O$ abandono da hipnose não levou ao fim da influência sugestiva, que passou a aparecer na forma de transferência. Atento a isto, Freud alertou:

Recusamo-nos, da maneira mais enfática, a transformar um paciente, que se coloca em nossas mãos em busca de auxílio, em nossa propriedade privada, a decidir por ele o seu destino, a impor-lhe os nossos próprios ideais e, com o orgulho de um Criador, a formá-lo à nossa própria imagem e verificar que isso é bom. (Freud, $1919[1918] / 1996$, p. 207)

Desse modo, o endereçamento feito pelo paciente no tratamento não deve servir ao engrandecimento dos objetos por ele investido. Ser um "Criador" equivale a tornar-se um objeto onipotente, juiz do caminho a ser seguido em direção a um Bem. Nesse sentido, não é indiferente a escolha deste termo por Freud, que remete a Deus. Criador do homem a sua própria imagem e semelhança.

O que algumas instituições promovem senão esta veneração a um objeto exclusivo? Ao invés de Deus, um outro Criador ocupa o lugar de saber. Mannoni (1971) salienta que em estabelecimentos de saúde mental uma doença "institucional" pode acrescentar-se aos sintomas iniciais do paciente, fixando-os de modo anormal. Para que não seja abandonado pela "psiquiatria", o paciente busca manter-se sendo tratado de modo a continuar doente.

Freud (1916-1917/1996) já apontava que, algumas vezes, a doença torna-se útil e adequada a tal ponto que adquire uma segunda função que reforça sua estabilidade. No caso das neuroses, uma espécie de exploração secundária de uma doença levaria a dificuldades no tratamento desta.

Se não há espaço para que a angústia desdobre-se pela fala, o indivíduo busca apaziguarse pelo o que lhe é oferecido: benefícios e objetivações diagnósticas. Mantendo a "desordem mental" em repouso através de uma ordenação de como proceder, o tratamento pode velar os conflitos psíquicos que estão na base dos sintomas. Para atingir a cura, restabelecendo a saúde, seria necessário submeter-se às prescrições dos profissionais.

Já em 1908 ao examinar as consequências de uma moral sexual civilizada, Freud comenta que uma das injustiças sociais recorrentes na cultura é a exigência de uma conduta sexual idêntica para todos os indivíduos. Para alguns, isto não representaria grandes esforços, mas para outros o sacrifício levaria a desobediência às junções morais através de satisfações substitutivas, na forma de sintomas patológicos.

Em 1930, Freud amplia essas considerações ao dizer que ao longo do movimento civilizatório todos exprimem algum tipo de sintoma decorrente do mal-estar incrementado pela renúncia pulsional vigente enquanto ordem. A fim de não sucumbir ao estado de desamparo, próprio ao 
humano, o indivíduo concorda com o compromisso que o leva a abdicar da realização de seus impulsos sexuais.

De acordo com Birman (1997, p. 72), na tentativa de lidar com essas imposições a civilização construiu mecanismos de alívio para o desprazer instaurado, como os psicofármacos. Ao proporcionar uma "sedação generalizada da angústia humana", eles acarretariam o silenciar das diferenças. Nas instituições psiquiátricas é comum que para um dado diagnóstico seja administrado um mesmo medicamento, como se os sintomas seguissem uma padronização que não dissesse respeito à singularidade de cada paciente. Para atingir, desse modo, um bem-estar propaga-se a necessidade de homogeneização do sofrimento, deixando-se de lado o que cada um pode dizer sobre si.

\section{Uma nova cronificação na retaguarda da inclusão social: bem-estar e bem-dizer}

No cenário do pós-segunda Guerra Mundial a psiquiatria passou a balizar-se pelo contexto de "reliberação", através da perspectiva social de igualdade e liberdade. Novas possibilidades começaram a construir-se, opondo-se à psiquiatria repressora e fisicalista que tomava a institucionalização como principal forma de tratamento. A necessidade de desinstitucionalizar para cuidar circulou como emblema pelo mundo. Nos Estados Unidos, surgiram as comunidades terapêuticas. Na França, a psicoterapia comunitária, como modo de "dar voz" aos doentes mentais. Na Itália, no final da década de 1960, a psiquiatria democrática, tendo como principal representante Franco Basaglia (Venancio, 1993).

No Brasil, foi na década de 1970 em meio a críticas sobre o funcionamento dos hospícios e da ineficiência da assistência pública em saúde que reformulações institucionais e políticas geraram a implementação de serviços substitutivos ao modelo clássico em saúde mental. Os grandes hospitais deram lugar à redução de leitos com atividades de atenção diária (Dunker \& Neto, 2004).

O objetivo tornou-se garantir os direitos dos usuários, promovendo sua cidadania. Da exclusão à inclusão social, o corpo passível de tratamento passou àquele que se utiliza de um serviço ${ }^{2}$. Nesse sentido, o Estado e o saber público, representados pelos novos serviços, buscam responder às reivindicações dos usuários e familiares. O sofrimento, até então individualizado, expresso pela demanda de cura, altera-se através da demanda de inclusão, isto é, desvia-se de carências isoladas para necessidades de uma classe. O que passa a ser visado é a inclusão na comunidade, por um movimento de base social da reforma psiquiátrica.

O tratamento para a doença mental dependeria, assim, nesses moldes, da reinserção social do usuário, bem como da retomada de seu poder de produção. Este é, por exemplo, o lema defendido por Basaglia: "Não se cura o doente com subjetividade, mas se cura na volta ao círculo produtivo" (1979, p. 93, apud Dunker \& Neto, 2004).

Os termos "cidadão" e "trabalhador" ganham, dessa forma, uma positividade, em relação aos termos "paciente" e "doente". Mudanças que objetivam aproximar a identidade daqueles que 
sofrem da sociedade em geral. A possibilidade de envolver-se em atividades terapêuticas, aprender e trabalhar guiaria o usuário de volta ao cerne do convívio social.

Freud (1930/2014) ressalta como a vida em sociedade no desenvolvimento da civilização foi possível pela coação dos indivíduos ao trabalho e pelas grandes modificações psíquicas da função do amor, afastando-se de sua meta sexual em direção a impulsos de meta inibida, enquanto ternura. Desse modo, percebe-se como a reforma psiquiátrica aproxima-se desse redirecionamento pulsional, porém como isto aparece, muitas vezes, em oposição às singularidades de cada usuário. Se a cura não se faz pela subjetividade, a dimensão clínica reduz-se a buscar suprir demandas que visam aumentar a produtividade do indivíduo (Dunker \& Neto, 2004).

A fala que poderia abrir-se para um não saber, incitando um trabalho psíquico de deciframento (Chauí, 2001), passa a concentrar-se na produção de demandas. Serviços ofertam benefícios que pela lógica capitalista criam mais demandas. Os psicofármacos, por este viés, tornamse um direito requerido pelo usuário-cidadão. Se antes havia uma repulsão contra o tratamento prescrito e forçado a ele, agora a oferta com o ideal de inclusão social o leva a querer e mesmo necessitar de atendimento (Dunker \& Neto, 2004).

Em que medida, contudo, este tratamento deixa de ser imposto ao sujeito? Quem decide o que é ou não válido à inclusão do usuário continua a ser o agente externo a ele, isto é, o profissional. É ele quem estabelece como o usuário pode libertar-se da alienação na qual viveu por tanto tempo. "Como libertar o outro, no entanto, se ele é objeto de um discurso de liberdade? Como fazê-lo reconhecer-se em um discurso do qual ele não é, em primeira instância, o produtor, mas o reprodutor?" (Dunker \& Neto, 2004, p. 121).

Por mais que não se note, a preocupação com o bem-estar imbuída na necessidade de inclusão social requer certa obediência do indivíduo quanto ao tratamento, mesmo que se faça com o consentimento deste. Na tentativa de produzir condições que assegurem o Bem dos usuários, legitimando as ações dos serviços e do Estado, acaba-se por desconsiderar as subjetividades de cada envolvido (Rinaldi, 2006).

O que se torna reconhecido, dessa maneira, é o poder do tratamento, já que o usuário permanece dependente da disponibilidade dos serviços. Portanto, ter sua cidadania atestada não garante a liberdade, a potência de suas pulsões, pois sua satisfação deve decorrer do trabalho social que o leva a incluir-se na comunidade. É requerida dele, nesse sentido, a sublimação de seus impulsos; que obtenha satisfação de uma determinada forma, não se pervertendo rumo a seu bemestar. Entretanto, este processo sublimatório não seria o destino privilegiado de uma realização satisfatória da pulsão, podendo acarretar, segundo Freud (1908/1996), um acréscimo do mal-estar.

Isto está de acordo com o aumento do número de pacientes que se encontram em tratamento por longos anos, relatando a piora de seus sintomas. Este panorama configura parte da cronificação que se observa, mesmo com as mudanças institucionais e políticas observadas. Se a ética do bem-estar opõe-se aos espaços de fala, de subjetivação, pois o que é assegurado são modos 
específicos de prazer, a psicanálise adentra as instituições na contramão deste processo. Sem negar que o homem busca encontrar a felicidade, ela orienta-se pela inatingibilidade dessa união. A completude the é interditada por sua própria condição de humano, ser na linguagem (Alves, 2000).

Um objeto total que assegure a satisfação última do indivíduo está desde sempre perdido, e é por essa inacessibilidade que o desejo faz-se onipresente. O bem-estar, nessa medida, só tem consistência pelo registro imaginário, que como um ideal a ser atingido sustenta as promessas de possibilidade de plenitude.

Se o usuário agir de determinada forma poderá ser incluído socialmente e será bem-sucedido em seu tratamento. Se ele falha neste caminho é porque os objetos à disposição não foram eficazes em seu objetivo. O que a psicanálise vem apontar é que de partida todos os objetos fracassam, pois não há saber que assegure as satisfações pulsionais. O que a ética do bem-dizer marca como alternativa é a arte de cercar a falta estrutural que surge da não relação entre sujeito e objeto, isto é, da incompletude de satisfação. É da fala recolhida em uma escuta que sublinha sua importância que o desejo pode emergir. Para Miller o desejo é "o que não conseguimos dizer dentro do que falamos" (Miller, 1997, p. 449).

\section{Considerações finais}

Dessa forma, por mais que não haja um bem-estar último possível aos usuários, uma escolha ética pode ser empreendida, desde que exista lugar para tal, enquanto vazio a ser preenchido pelo sujeito, e não pelo analista ou pela instituição. A ética do bem-dizer não é pessimista. Pelo contrário, ela autentica não recuar diante da falta de palavras. Faz-se como um esforço contínuo de dizer o que se tem para dizer mesmo que não existam palavras para tal (Alves, 2000).

Acredita-se, assim, que pela discussão das mudanças propostas pela reforma psiquiátrica seja possível posicionar-se por uma não oposição criada entre a inclusão social do usuário e a expressão de sua subjetividade, que pode ficar excluída do tratamento. Pela fala outras condições de satisfação podem ser formuladas pelo paciente. Crer que um novo funcionamento das instituições de saúde mental trouxe uma liberdade para o usuário, já que agora ele reivindica seu tratamento e não mais o recusa é manter-se na ilusão da eficiência dos serviços regidos pela lógica do capital.

Dar voz à singularidade não é o mesmo que permitir um espaço onde o usuário consome os objetos ofertados, sejam eles medicamentos ou diferentes formas de benefícios. Pelo processo de cronificação, atrelado ao agravamento dos sintomas, percebe-se como os pacientes mesmo demandando tratamento opõem-se às exigências impostas pelos serviços. Ao analisar essas questões, as dimensões da singularidade, do desejo e da força da pulsão sexual podem ter lugar junto ao saber produzido não em nome do sujeito, mas por ele. Essa é a aposta.

\section{Notas:}


${ }^{1}$ Por porta de entrada compreende-se o processo de triagem que pode ser, ou não, acompanhado por grupos de admissão formados por usuários que buscam tratamento em determinada instituição. Para que sejam admitidos ou encaminhados a outros serviços são avaliados por alguns profissionais, afim de que suas demandas sejam formuladas com maior clareza.

${ }^{2}$ Do latim servitium, significando escravidão, servidão. É interessante a oposição que irá manter-se. Antes o paciente com seu corpo, objeto de investigação, agora é um usuário que se vale de um serviço. Se antes era escravo de um sistema exclusivo, formalizado para ele, e excludente, agora é senhor cidadão que se serve de objetos a seu dispor. Ver-se-á as implicações disto mais adiante.

\section{Referências Bibliográficas}

Alves, J. M. R. (2000, abr.). Sobre uma ética do bem dizer. Carta ACF, (15). Recuperado de http://acfportugal.com/menu/textos.htm.

Barros, R. B. de. (2003). Reforma psiquiátrica brasileira: resistências e capturas em tempos neoliberais. In Conselho Federal de Psicologia (Org.). Loucura, ética e política: escritos militantes (pp. 196-206). São Paulo: Casa do Psicólogo.

Brasil. (2001, abr.). Lei n. 10.216. Recuperado de http://www.planalto.gov.br/ccivil_03/leis/leis_2001//10216.htm

Birman, J. (1997). Estilo e modernidade em psicanálise. São Paulo: Ed. 34.

Birman, J. (2010a). Perversão e Transgressão. In $18^{\circ}$ Congresso do Círculo Brasileiro de Psicanálise. A Psicopatia da Vida Cotidiana. Rio de Janeiro: CBP (Gravação em DVD).

Birman, J. (2010b). Discurso freudiano e medicina. In Birman, J.; Fortes, I; Perelson, S. Um novo lance de dados. Psicanálise e medicina na contemporaneidade (pp. 13-46). Rio de Janeiro: Cia. De Freud.

Chauí, M. (2001). Cultura e Democracia. O Discurso Competente e Outras Falas. São Paulo: Cortez Editora.

Desviat, M. (1999). A reforma psiquiátrica. Rio de Janeiro: Editora Fiocruz.

Dunker, C. I. L. \& Neto, F. K. (2004). Sobre a Retórica da Exclusão: a Incidência do Discurso Ideológico em Serviços Substitutivos de Cuidado a Psicóticos. Revista psicologia, ciência e profissão, 1(24), 116-125.

Freud, S. (1996). Três ensaios sobre a teoria da sexualidade. In J. Salomão (Trad.) Edição standard brasileira das obras psicológicas completas de Sigmund Freud (Vol. 7, pp. 118-230). Rio de Janeiro: Imago (Trabalho original publicado em 1905).

Freud, S. (1996). Moral sexual civilizada e doença nervosa. In J. Salomão (Trad.) Edição standard brasileira das obras psicológicas completas de Sigmund Freud (Vol. 9, pp. 185-210). Rio de Janeiro: Imago (Trabalho original publicado em 1908). 
Freud, S. (1996). Dinâmica da transferência. In J. Salomão (Trad.) Edição standard brasileira das obras psicológicas completas de Sigmund Freud (Vol. 12, pp. 131-146). Rio de Janeiro: Imago (Trabalho original publicado em 1912).

Freud, S. (1996). Observações sobre o amor transferencial (novas recomendações sobre a técnica da psicanálise III). In J. Salomão (Trad.) Edição standard brasileira das obras psicológicas completas de Sigmund Freud(Vol. 12, pp. 207-221). Rio de Janeiro: Imago (Trabalho original publicado em 1915[1914]).

Freud, S. (2004). Pulsões e Destinos da Pulsão. In L. A. Hanns (Trad.) Escritos sobre a psicologia do inconsciente (Vol. 1, pp. 133-173). Rio de Janeiro: Imago (Trabalho original publicado em 1915).

Freud, S. (1996). Conferências introdutórias sobre psicanálise. Conferência XXVII: Transferência. In J. Salomão (Trad.) Edição standard brasileira das obras psicológicas completas de Sigmund Freud (Vol. 16, pp. 503-522). Rio de Janeiro: Imago (Trabalho original publicado em 19161917).

Freud, S. (1996). Linhas de progresso na terapia psicanalítica. In J. Salomão (Trad.) Edição standard brasileira das obras psicológicas completas de Sigmund Freud (Vol. 17, pp. 199-214). Rio de Janeiro: Imago (Trabalho original publicado em 1919[1918]).

Freud, S. (2013). Psicologia das massas e análise do eu. In R. Zwick (Trad.) Porto Alegre: L\&PM (Trabalho original publicado em 1921).

Freud, S. (2014). O mal-estar na cultura. In R. Zwick (Trad.) Porto Alegre: L\&PM (Trabalho original publicado em 1930).

Freud, S. (1996). Análise terminável e interminável. In J. Salomão (Trad.) Edição standard brasileira das obras psicológicas completas de Sigmund Freud (Vol. 23, pp. 239-288). Rio de Janeiro: Imago (Trabalho original publicado em 1937).

Foucault, M. (2009). História da Sexualidade. São Paulo: Graal.

Lopes, A. J. (2011, jul.). Breve introdução a uma história da libido: Poetas Latinos, Santo Agostinho e Freud (via Foucault). Estudos de Psicanálise, (35), 23-40.

Mannoni, M. (1971). O psiquiatra, seu "louco" e a psicanálise. Rio de Janeiro: Zahar ed.

Miller, J.-A. (1997). Lacan Elucidado: Palestras no Brasil. Rio de Janeiro: Zahar ed.

Ministério da saúde. (2010). Saúde Mental em Dados 7. Brasília: Autor.

Rinaldi, D. (2006). Entre o sujeito e o cidadão: psicanálise ou psicoterapia no campo da saúde mental? In Alberti, S. \& Figueiredo, A. C. (Orgs.). Psicanálise e Saúde Mental: uma aposta. (pp. 141-147). Rio de Janeiro: Companhia de Freud.

Santos, Y. (2007). O ambulatório de saúde mental no contexto da reforma psiquiátrica em Natal/RN. (Dissertação de mestrado não publicada). Universidade Federal do Rio Grande do Norte, Rio Grande do Norte. 
Severo, A. K. (2009). A cronificação nos serviços substitutivos na rede de saúde mental de Natal $R N$. (Dissertação de Mestrado). Retirado da Base de Dados da UFRN.

Venancio, A. T. A. (1993). A construção social da pessoa e a psiquiatria: do alienismo à "nova psiquiatria". Physis, 3(2), 117-136.

Citacão/Citation: Kushnir, C. Q. (nov. 2015 a abr. 2016). Freud e a Grécia antiga: uma leitura do processo de cronificação em saúde mental. Revista aSEPHallus de Orientação Lacaniana, 11(21), 102-114. Disponível em www.isepol.com/asephallus. doi: 10.17852/1809-709x.2019v11n21p102-114.

Editor do artigo: Tania Coelho dos Santos.

Recebido/Received: 24/02/2016 / 02/24/2016.

Aceito/Accepted: 18/03/2016 / 03/18/2016.

Copyright: (C) 2013 Associação Núcleo Sephora de Pesquisa sobre o moderno e o contemporâneo. Este é um artigo de livre acesso, que permite uso irrestrito, distribuição e reprodução em qualquer meio, desde que o autor e a fonte sejam citados/This is an open-access article, which permites unrestricted use, distribution, and reproduction in any medium, provided the author and source are credited. 